Gut, 1987, 28, 896-899

Case reports

\title{
Acute ischaemic colitis in a female long distance runner
}

\author{
M HEER, F REPOND, A HANY, H SULSER, O KEHL, AND K JÄGER \\ From the Departments of Medicine and Pathology, Kantonsspital Winterthur, Switzerland and the Department \\ of Medicine, University Hospital, Zürich, Switzerland
}

SUMmARY A 34 year old female long distance runner is reported with bloody diarrhoea. Colonoscopy revealed patchy haemorrhagic mucosal lesions throughout the colon. The most extensive lesions were found in the sigmoid colon. Histologic examination disclosed mucosal haemorrhage, dilated capillaries, patchy fibrosis and superficial erosions. Additional findings in this patient were haemorrhagic gastritis, microscopic haematuria and rhabdomyolysis. The only medication taken by the patient was oral contraceptives. We conclude that ischaemic colitis is one of the possible mechanisms leading to gastrointestinal blood loss in competitive runners.

\begin{abstract}
Abdominal discomfort and alteration in gastrointestinal function are common in runners. Twenty five per cent of runners had abdominal cramps or diarrhoea in association with competitive running.' Although occult gastrointestinal bleeding seems to be quite common ${ }^{2-5}$ bloody diarrhoea remains a rare event. ${ }^{\star}$ The pathophysiology of gastrointestinal bleeding during physical exercise is poorly understood, but bowel ischaemia has been proposed as a possible mechanism..$^{2-69}$ We report on a female long distance runner with a bloody diarrhoea syndrome caused by acute ischaemic colitis.
\end{abstract}

\section{Case report}

A 34 year old female long distance runner was referred to our hospital because of bloody diarrhoea. She competed in a $15 \mathrm{~km}$ mountain race; the altitude ranged between 540 and $870 \mathrm{~m}$ and the temperature was 14 to $18^{\circ} \mathrm{C}$. At $10 \mathrm{~km}$ she experienced generalised severe crampy abdominal pains, forcing her to stop the race. During the next hour she noted bloody red stools, over the next few hours she subsequently vomited and noted small portions of blood. The same day she was referred for clinical evaluation. The patient had been in good health all

Address for correspondence: Martin Heer, MD, Gastrointestinal Unit, Department of Medicine, Kantonsspital, $\mathrm{CH}-84(0) 1$ Winterthur, Switzerland.

Received for publication 21 November, 1986 her life. She pursued distance running for two years and competed in cross country, averaging $50-60 \mathrm{~km}$ of training runs per week. Her best time for $22 \mathrm{~km}$ was 1:27. She had previously experienced less severe abdominal cramping with running. The only medication was an oral contraceptive (Ovanon, Ercopharm, Kopenhagen, Denmark). The dosage was ethinylestradiol $0.05 \mathrm{mg} / \mathrm{d}$ for seven days and ethinylestradiol $0.05 \mathrm{mg}$ with lynestrol $2.5 \mathrm{mg} / \mathrm{d}$ for 15 days, which she had been taking for 10 years before admission. She was taking no other medication and was a non-smoker. Physical examination was unremarkable, the blood pressure was $100 / 60 \mathrm{mmHg}$ and the pulse rate was 84 beats per minute, the temperature was $36 \cdot 6^{\circ} \mathrm{C}$. The blood group was $\mathrm{AB}$. The haemoglobin was $15.1 \mathrm{~g} / \mathrm{dl}$, the thrombocyte counts were $165000 / \mathrm{mm}^{3}$ (normal 150000 $\left.35000 / \mathrm{mm}^{3}\right)$; the leucocyte count was $22000 / \mathrm{mm}^{3}$ (normal: $4000-10000 / \mathrm{mm}^{3}$ ) with $87 \%$ neutrophils, $7 \%$ monocytes, $6 \%$ lymphocytes. The prothrombin time was $57 \%$. Aspartate aminotransferase (AST) was 92 IU/l (normal: 13-38 IU/l), alanine aminotransferase (ALT) was $36 \mathrm{IU} / \mathrm{l}$ (normal: 11-40 IU/l), lactic dehydrogenase was 491 IU/l (normal: 90-350 IU/l), creatine phosphokinase was 1270 IU/l (normal: 24-184 IU/l), creatinine was $130 \mu \mathrm{mol} / \mathrm{l}$ (normal: $44-106 \mu \mathrm{mol} / \mathrm{l}$ ). Normal values were found for sodium, potassium, calcium, inorganic phosphorus and alkaline phosphatase. HBs-antigen was negative. Urinalysis was normal. Stool cultures were 


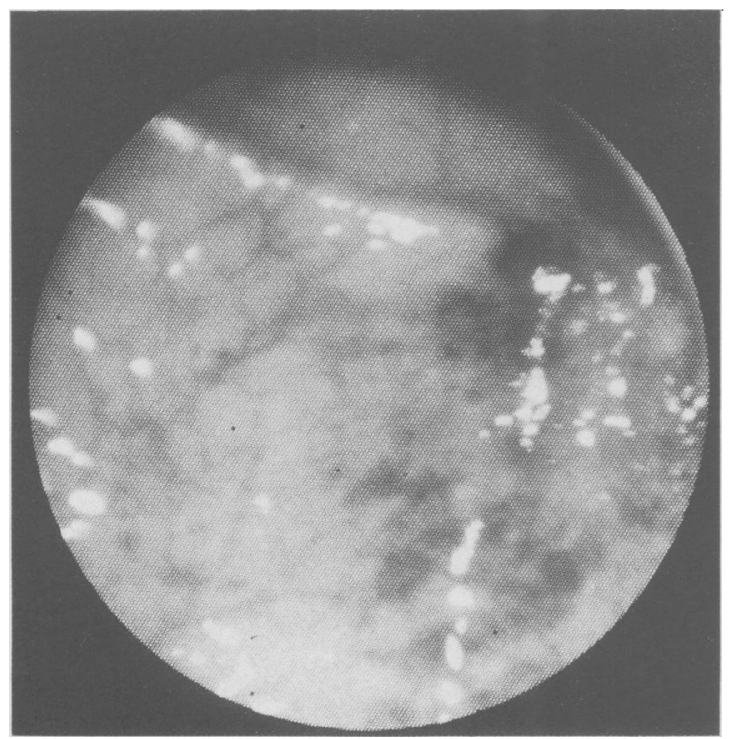

Fig. 1 Endoscopic appearance of acute ischaemic colitis with extensive patchy and punctate haemorrhage and neighbouring intact mucosa. No ulcers were seen.

negative for salmonella and shigella. No treatment was given. On the second day of admission aspartate aminotransferase increased to $321 \mathrm{IU} / \mathrm{l}$, creatine phosphokinase was $1500 \mathrm{IU} / \mathrm{l}$. Fractionation of creatine phosphokinase showed the MB fraction (cardiac fraction) to be normal. The lactic dehydrogenase was $733 \mathrm{IU} / \mathrm{l}$. The rectal bleeding and abdominal pain subsided over the 72 hours after admission. She remained afebrile. On the third day of admission haemoglobin value slightly decreased to 14.7 $\mathrm{g} / \mathrm{dl}$, the leucocyte count was $6800 / \mathrm{mm}^{3}$, creatine phosphokinase was $459 \mathrm{IU} / \mathrm{l}$ and creatinine was 95 $\mu \mathrm{mol} / \mathrm{l}$. Urinalysis disclosed microscopic haematuria with eight to 12 red blood cells per high powered field. A gastroscopy was done and patchy haemorrhagic mucosal lesions were found at the great curvature of gastric corpus and a typical Mallory-Weiss lesion at the gastroesophageal junction. On the third day of admission colonoscopy was done after preparation of the colon with a bowel cleansing solution. ${ }^{10}$ Colonoscopic examination disclosed thickened, oedematous mucosal folds with patchy mucosal haemorrhage in the ascending, transverse, and descending colon. Most extensive lesions were found in the sigmoid colon (Fig. 1), but in the rectum moderate granularity and oedema of the mucosa was noted. Histological examination revealed extensive mucosal haemorrhage, dilated capillaries, patchy fibrosis and superficial erosions (Fig. 2). Haemosiderin loaded macrophages were not found. She tapered her running schedule for two weeks and continued taking her oral contraceptive against medical advice. Two months after admission a follow up colonoscopy was done, with normal findings. Histologic examinations revealed patchy mucosal atrophy, fibrosis and scars, suggesting a healed state of mucosal ischaemia with incomplete recovery. Haemosiderin loaded macrophages were not seen.

MEASUREMENT OF MESENTERIC BLOOD FLOW After the patient had reassumed a regular training schedule, an exercise test on a treadmill was performed $\left(10 \mathrm{~km}\right.$ average speed $15 \mathrm{~km} / \mathrm{h}$, grade $\left.0^{\circ}\right)$. Blood flow through the superior mesenteric artery and the abdominal aorta was non-invasively measured with an ultrasonic duplex scan" at rest and after the stress test. At rest superior mesenteric blood flow was at the lower normal limit $(3.6 \mathrm{ml} / \mathrm{s})$ and dropped to $2.6 \mathrm{ml} / \mathrm{s}(70 \%) 15$ minutes after exercise. Aortic blood flow increased from $11.2 \mathrm{ml} / \mathrm{s}$ to 32.1 $\mathrm{ml} / \mathrm{s}(285 \%)$. The ratio mesenteric/aortic blood flow dropped from 1.0 at rest to 0.2 after the stress test. Aortic and mesenteric blood flow was normalised 60 minutes after the exercise test.

\section{Discussion}

We report on a female long distance runner with bloody diarrhoea and acute ischaemic colitis. The diagnosis of acute ischaemic colitis was based on the endoscopic appearance of patchy haemorrhagic mucosal lesions with neighbouring intact mucosa, the histologic features of mucosal haemorrhage, dilated capillaries, punctate erosions, the lack of a history of antecedent diarrhoeal illness, the rapid spontaneous recovery, the endoscopic and histologic findings during follow up colonoscopy. Other complications in this patient, previously reported in long distance runners, such as haemorrhagic gastritis, ${ }^{12}$ haematuria ${ }^{43^{1+}}$ and rhabdomyolysis ${ }^{16}{ }^{17}$ show a multisystem involvement. Although iron deficiency, with or without anaemia and occult bleeding seems to be quite common in marathon runners ${ }^{2-5} 18$ bloody diarrhoea remains a rare event. ${ }^{\perp *}$ To the best of our knowledge it seems to be the first case of a runner with endoscopically diagnosed acute ischaemic lesions of the whole colon. Mucosal haemorrhage, dilated capillaries and punctate erosions initially seen in our patient are typical features of acute ischaemic colitis ${ }^{19}$ whereas patchy fibrosis demonstrate chronic and repeated ischaemic injuries of the mucosa. One case of a marathon runner has been reported with endoscopically diagnosed thickened oedematous mucosal fold in the caecum.' Histologic findings with patchy mucosal atrophy and fibrosis 


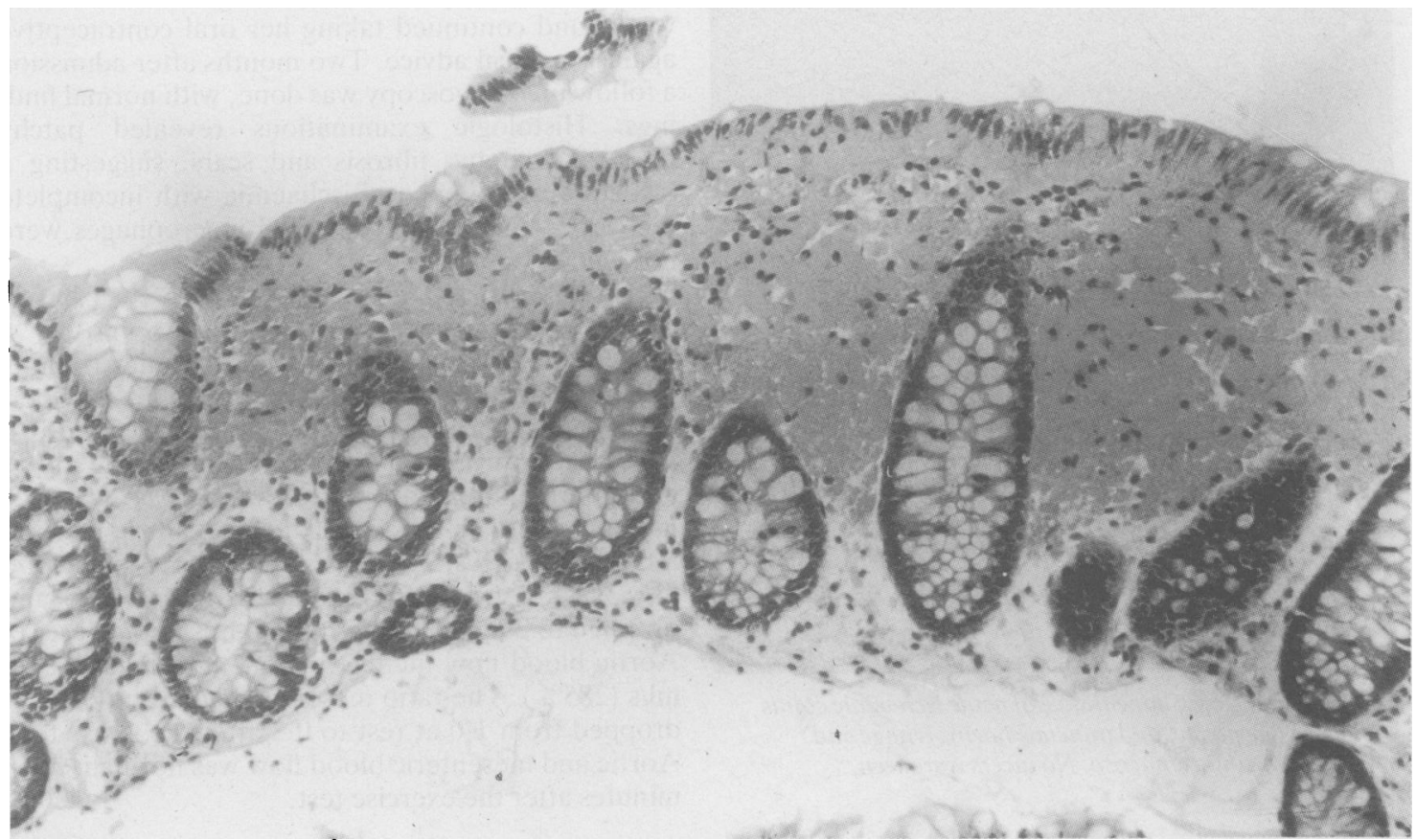

Fig. 2 Histologic examination of sigmoid colon reveals extensive mucosal haemorrhage with preservation of the crypts. $(\mathrm{H} \& \mathrm{E})$

resembled those seen in our patient during follow up colonoscopy, suggested a healed state with incomplete recovery. These cases add further evidence to the hypothesis that running induced bleeding is caused by transient gut ischaemia. ${ }^{2-69}$ In our patient aortic and mesenteric blood flow was evaluated before and after an exercise test on the treadmill. The patient ran $10 \mathrm{~km}$ in 42 minutes and did not experience any symptoms. Although the level of exercise may be considered as a mild work load for a long distance runner, her superior mesenteric blood flow decreased by $30 \%$ after the run. In another symptomatic patient we found a decrease in mesenteric blood flow of $80 \%$ in response to a more vigorous exercise. ${ }^{y}$ A large number of intrinsic and extrinsic mechanisms are known to control intestinal blood flow. 2" Some of these - for example, metabolites, electrolytes, catecholamines, sympathetic nervous system may well have triggered the ischaemic lesions.

A point that merits further comment is the oral contraceptive taken by the patient. Small bowel ischaemia and ischaemic colitis have been reported in young women taking oral contraceptives. ${ }^{21.2 x}$ In almost all these cases the patients had no predisposing disorders. The role of oral contraceptives in the evolution of the ischaemic colitis seen in our patient remains unclear but may have been a predisposing factor.

We conclude that competitive long distance running occasionally induces acute ischaemic colitis with gastrointestinal blood loss which might contribute to iron deficiency and sports anaemia.

The authors thank Ms E Burri for technical assistance and Ms M Krebser for preparation of the manuscript.

\section{References}

1 Sullivan SN. The gastrointestinal symptoms of running. [Letter]. N Engl J Med 1981; 304: 915.

2 Stewart JG, Ahlquist DA, McGill DB, Ilstrup DM, Schwartz S, Owen RA. Gastrointestinal blood loss and anemia in runners. Ann Intern Med 1984; 100: 843-5.

3 McMahon LF, Ryan MJ, Larson D, Fisher RL. Occult gastrointestinal blood loss in marathon runners. Ann Intern Med 1984; 100: 846-7.

4 Porter AMW. Do some marathon runners bleed into the gut? Br Med J 1983; 287: 1427.

5 Volpicelli N. Effects of sports on the gastrointestinal tract and liver. In: Appenzeller O, Atkinson R, eds. Sports medicine: fitness, training, injuries. BaltimoreMunich: Urban \& Schwarzenberg, 1983: 91-8. 
6 Fogoros RN. Runner's Trots. Gastrointestinal disturbances in runners. JAMA 1980; 243: 1743-4.

7 Schaub N, Spichtin HP, Stalder GA. Ischämische Kolitis als Ursache einer Darmblutung bei Marathonlauf? Schweiz Med Wochensch 1985; 115: 454-7.

8 Cantwell JD. Gastrointestinal disorders in runners. [Letter]. JAMA 1981; 246: 1404-5.

9 Kehl O, Jäger KA, Münch $\mathrm{R}$, et al. Mesenteriale Ischämie als Ursache der "Jogging-Anämie"? Schweiz Med Wochensch 1986; 116: 974-6.

10 Davis GR, Santa Ana CA, Morawski SG, Fordtran JS. Development of a lavage solution associated with minimal water and electrolyte absorption or secretion. Gastroenterology 1980; 78: 991-5.

11 Jäger K, Bollinger A, Valli C, Ammann R. Measurement of mesenteric blood flow by duplex-scanning. $J$ Vasc Surg 1986; 3: 462-9.

12 Thompson PD, Funk EJ, Carleton RA, Sturner WQ. Incidence of death during jogging in Rhode island from 1975 through 1980. JAMA 1982; 247: 2535-8.

13 Papioannides D, Giotis C, Karagiannis N, Voudouris C. Acute upper gastrointestinal hemorrhage in longdistance runners. Ann Intern Med 1984; 101 : 719.

14 Blacklock NJ. Bladder trauma in the long-distance runner: "10'000 metres haematuria!" BrJ Urol 1977; 49: 129-32.

15 Siegel AJ, Hennekens $\mathrm{CH}$, Solomon HS, Van Boeckel B. Exercise-related hematuria. Findings in a group of marathon runners. JAMA 1979; 241: 391-2.

16 Schiff HB, Mc Searraigh ETM, Kallmeyer JC. Myoglobinuria, rhabdomyolysis and marathon running. $Q J$ Med 1978; 188: 463-72.
17 Bunch TW. Blood test abnormalities in runners. Mayo Clin Proc 1980; 55: 113-7.

18 McCabe ME, Peura DA, Kadakia SC, Bocek Z, Johnson LF. Gastrointestinal bleeding in long distance runners. [Abstract]. Gastroenterology 1984; 86: 1178.

19 Whitehead R. The pathology of intestinal ischaemia. Clin Gastroenterol 1972; 1: 613-37.

20 Granger DN, Richardson PDI, Kvietys PR, Mortillaro NA. Intestinal blood flow. Gastroenterology 1980; 78: 837-63.

21 Kilpatrick ZM, Silverman JF, Betancourt E, Farman J, Lawson JP. Vascular occlusion of the colon and oral contraceptives. N Engl J Med 1968; 278: 438-40.

22 Hurwitz RL, Martin AJ, Grossman BE, Waddell WR. Oral contraceptives and gastrointestinal disorders. Ann Surg 1970; 172: 892-6.

23 Cotton PB, Thomas ML. Ischaemic colitis and the contraceptive pill. Br Med J 1971; 3: 27-8.

24 Gelfand MD. Ischemic colitis associated with a depot synthetic progestogen. Am J Dig Dis 1972; 17: 275-7.

25 Morowitz DA, Epstein BH. Spectrum of bowel disease associated with use of oral contraceptives. Med Ann DC 1973; 42: 6-10.

26 Hoyle M, Kennedy A, Prior AL, Thomas GE. Small bowel ischaemia and infarction in young women taking oral contraceptives and progestational agents. BrJ Surg 1977; 64: 533-7.

27 Ischemic disease of the colon and oral contraceptives Medical staff conference, University of California, San Francisco. West J Med 1977; 126: 378-85.

28 Tedesco FJ, Volpicelli NA, Moore FS. Estrogen- and progesterone-associated colitis: A disorder with clinical and endoscopic features mimicking Crohn's colitis. Gastrointest Endoscopy 1982; 28: 247-9. 